\title{
Distribution and Propagation of Hepatitis E Virus in Experimentally Infected Swine
}

\author{
Katsuro Hagiwara*,a, Yukie Iwabu ${ }^{\mathrm{b}}$, Yuta Kanai ${ }^{\mathrm{a}}$, Taku Miyasho ${ }^{\mathrm{a}}$, Tomo Daidoji ${ }^{\mathrm{b}}$, Mikihiro \\ Yunoki $^{\mathrm{c}}$, Muneo Tsujikawa ${ }^{\mathrm{c}}$, Yuuji Ohkubo ${ }^{\mathrm{c}}$, Hiroshi Yasue ${ }^{\mathrm{d}}$ and Kazuyoshi Ikuta ${ }^{\mathrm{b}}$
}

\author{
${ }^{a}$ School of Veterinary Medicine, Rakuno Gakuen University, Ebetsu, Hokkaido 069-8501 Japan, ${ }^{b}$ Department of Virol- \\ ogy, Research Institute for Microbial Diseases, Osaka University, 3-1 Yamadaoka, Suita, Osaka 565-0871, Japan, ${ }^{c}$ In- \\ fectious Pathogen Research Group, Hirakata Research Laboratory, Research \& Development Division, Benesis Corpo- \\ ration, 2-25-1, Shodai-Ohtani, Hirakata, Osaka 573-1153, Japan, ${ }^{d}$ Genome Research Department, National Institute of \\ Agrobiological Sciences, Tsukuba, Ibaraki, 305-0901 Japan
}

\begin{abstract}
HEV infections in human and pigs have been reported in many countries; however, the precise distribution and multiplication of this virus in the host remains poorly understood. In this study, we examined the distribution and multiplication of HEV genotype 3 in two piglets at the early phase of intravenous infection, and also examined the virus distribution in a naturally infected pig. We developed real-time RT-PCR to determine copy numbers of the HEV genome in the sera, feces and organs. HEV-RNA was detected in serum from a pig transiently for 7 days post-inoculation (dpi). The HEV copy numbers in the feces appearing 7 dpi were increased to $3.4 \times 10^{6}$ copies/g at $14 \mathrm{dpi}$. In contrast, the higher copy numbers of HEV were widely distributed in the tissue organs from naturally HEV-infected pig. The study showed that intravenously inoculated HEV was distributed in several restricted tissues, such as in the liver and intestine.
\end{abstract}

Keywords: HEV, Pig, Experimental infection.

\section{INTRODUCTION}

Hepatitis E virus (HEV) is a small, non-enveloped virus, belonging to the Hepeviridae family [1]. The HEV genome is a single-stranded positive-sense RNA with approximately $7.2 \mathrm{~kb}$, containing a short $5^{\prime}$ noncoding region (NCR), three open reading frames (ORF1, ORF2 and ORF3), a short 3' NCR and a poly (A) tract [2]. Four different genotypes of HEV have been identified and such genotypes are distributed geographically. Epidemiological studies have reported that swine and human HEV from the US (genotype 3), Taiwan (genotype 4) and Japan (types 3 and 4) were identified as a similar genotype [3-5]. Two different HEV genotypes, 3 and 4, have been isolated from humans and pigs in Japan [6-10]. These virus infections induced hepatitis in humans who had eaten raw or undercooked wild deer, boar or pig livers [1116]. In addition, transfusion-transmitted HEV has been reported in several countries, including Japan [17-19], and retrospective and prospective studies have confirmed HEV infection in patients [20]. Epidemiological study among patients undergoing blood transfusion or hemodialysis patients showed the presence of HEV-RNA [8, 21]. These circumstances imply the possibility of iatrogenic transmission of HEV through contaminated blood transfusion; however, the precise distribution and proliferation of HEV in patients remains poorly understood. Naturally and experimental infection of HEV genotypes 1, 3 and 4 in Pigs have been reported in several countries, including Japan [22-27]. However, there is no experimental animal model to understand the distribution and multiplication of this virus. Therefore, a pig is the best animal model for the experimental infection of HEV. In

*Address correspondence to this author at the School of Veterinary Medicine, Rakuno Gakuen University, Ebetsu, Hokkaido 069-8501 Japan; E-mail: k-hagi@rakuno.ac.jp this study, we focus on the distribution and proliferation of $\mathrm{HEV}$ in pigs in the early phase of intravenous infection.

\section{MATERIALS AND METHODS}

\section{Viruses}

The swine HEV (genotype $3 \mathrm{jp}, 10^{6}$ copies per ml) used in this study was kindly provided by Dr. Tsunemitsu (National Institute of Animal Health, Japan). The HEV inoculum was serum derived from swine experimentally infected with HEV.

\section{Animals}

For the experimental infection of HEV (genotype 3), 2 large, white, specific pathogen-free (SPF) pigs, 7 and 10 weeks old (Pigs A and B), were reared at the experimental facility, in accordance with biosafety level 2 , for a week before experiment. The pigs were inoculated intravenously (i.v.) with $10^{5}$ copies of HEV-RNA. Serum and feces from each pig were collected at $4,7,11,14$ and 18 days postinoculation (dpi), respectively. The pigs were necropsied at 18 dpi. Seventeen different tissues and organs were collected from each animal including the liver, mesenteric and hepatic lymph nodes, gallbladder, small intestine, cecum, colon, rectum, spleen, heart, lung, kidney, and skeletal muscle. Samples of tissues and organs were treated with RNAlater (Qiagen $\mathrm{GmbH}$, Hilden, Germany) and frozen at $-80^{\circ} \mathrm{C}$ until used for PCR analysis. The liver samples were immediately fixed with ice-cold $4 \%$ paraformaldehyde for histopathological study. As a control, an age-matched SPF pig (Pig D) was also necropsied to examine for HEV-RNA according the methods described above. To compare virus distribution in pigs naturally infected with HEV (genotype 3), a 14-weekold mixbred pig (Pig C) was necropsied, and the tissues samples were collected as described above. The tissue sam- 
ples were examined for HEV-RNA and histopathology as described above. All animals were treated according to the Laboratory Animal Control Guidelines at Rakuno Gakuen University.

\section{RNA Extraction}

Total RNA was extracted from $50 \mathrm{mg}$ of tissue using TRIzol reagents (Invitrogen) and resuspended in $2 \mu \mathrm{l}$ of RNase-free water per $1 \mathrm{mg}$ of tissue. Total RNA in $1 \mathrm{ml} \mathrm{se}-$ rum was extracted with MagNA Pure LC Instrument (Roche Diagnostics) using MagNA LC Total Nucleic Acid Isolation Kit-Large Volume (Roche Diagnostics). Purified nucleic acid was eluted in $50 \mu \mathrm{l}$ of elution buffer. Viral RNA from stool and intestinal contents was isolated as follows: $50 \mathrm{mg}$ of the contents was suspended in $500 \mu \mathrm{l}$ of PBS. The suspension was centrifuged for $10 \mathrm{~min}$ at $13000 \mathrm{~g}$ and the supernatant was filtrated using a $0.22 \mu \mathrm{m}$ filter. Viral RNA was extracted from $140 \mu \mathrm{l}$ of the filtrate using QIAamp Viral RNA Mini Kit (Qiagen) and resuspended in $50 \mu 1$ of RNasefree water.

\section{Nested RT-PCR}

RT-PCR of the ORF1 region was performed by OneStep RT-PCR kit (Qiagen) in a $50 \mu 1$ reaction using 30 pmoles of outer primers, $10 \mu \mathrm{l} 5 \times$ buffer, $2 \mu 110 \mathrm{mM}$ dNTP, $40 \mathrm{U}$ RNase inhibitor, $2 \mu \mathrm{l}$ (tissue) or $5 \mu \mathrm{l}$ (intestinal contents) purified RNA and $2 \mu 1$ Enzyme Mix. RT-PCR reaction was carried out at $50^{\circ} \mathrm{C}$ for $30 \mathrm{~min}$, at $95^{\circ} \mathrm{C}$ for $15 \mathrm{~min}$, and 45 cycles $\left[95^{\circ} \mathrm{C}\right.$ for $15 \mathrm{sec}, 60^{\circ} \mathrm{C}$ for $30 \mathrm{sec}$, and $72^{\circ} \mathrm{C}$ for 30 sec]. Second-round reactions were carried out using TaKaRa Ex. Taq (Takara Bio) in $50 \mu \mathrm{l}$ volumes with $1 \mu \mathrm{l}$ first-round product, 10 pmol of inner primers, $5 \mu 110 \times$ Buffer, $4 \mu 12.5$ $\mathrm{mM}$ dNTP, $2.5 \mathrm{U}$ TaKaRa Ex Taq. Second-round amplification was carried out at $95^{\circ} \mathrm{C}$ for $2 \mathrm{~min}$ and 10 cycles $\left[94^{\circ} \mathrm{C}\right.$ for $15 \mathrm{sec}, 60^{\circ} \mathrm{C}$ for $30 \mathrm{sec}$, and $72^{\circ} \mathrm{C}$ for $15 \mathrm{sec}$ ]. The inoculated HEV strain-specific primers were used to detect ORF1 of samples of Pigs A and B. These primers were as follows: primer F (119-218 : 5'-CCCTGAGGTACTTTGGAATC-3') and primer R (358-341: 5'-AACTGGTCTGAGGAAGCA3') for first-round PCR and primer HE75 (219-239: 5'ATCCTATCCAGCGGGTTATAC) and primer HE76 (342$324: 5$ '-CACCGATGCAGAACATTGG-3') for secondround PCR (nucleotide positions corresponded to those of the swJ570 strain) [7]. Broadly reactive primers were used to detect ORF1 in samples from Pig C. These primers were: primer HE61 (7-31: 5'-CACRTATGTGGTCGAYGCCA TGGAG-3'; R:A/G, Y:T/C) and primer HE51 (131-111: 5'GCCKRACYACCACAGCATTCG-3'; K:T/G, R:A/G, Y: $\mathrm{T} / \mathrm{C}$ ) for first-round PCR and primer HE50 (47-66 5'AAGGCTCCTGGCRTYACWAC-3' R:A/G, Y:T/C, W: $\mathrm{A} / \mathrm{T}$ ) and primer HE51 for second-round PCR. PCR products were electrophoresed in 2\% agarose gel. Amplified cDNA (124 bp for Pigs A and B; 85 bp for Pig C) was stained by ethidium bromide $(0.5 \mu \mathrm{g} / \mathrm{ml})$ and visualized under UV illumination.

\section{Quantitative RT-PCR}

All representative samples of sera, feces and tissues were subjected to quantitative real-time RT-PCR. A standard curve for quantification of the swine HEV genome was generated using an in vitro swine HEV ORF1 cDNA plasmid. In vitro-transcribed RNA was quantitatively measured with a spectrophotometer. Serial 10 -fold dilutions from $10^{5}$ to $10^{2}$ copies were made and subjected to quantitative PCR. All representative samples were tested using LC RNA Amplification Kit Hybridization Probes (Roche Diagnostics) on the FRET protocol (Roche Diagnostics). The inoculated HEV strain-specific primers and probes used to detect ORF1 of samples of Pigs A and B were primer F, primer R, Probe Flu (281-307: 5'-TGTCTGGAGGTTGGAGCTCACCCGAGAFITC-3') and Probe LC (309-339 : 5'-LCRed640-CTATTA ATGACAACCCCAATGTTCTGCATCG-3'). The detection limit of this assay system was $10^{2}$ copies/reaction for tissues and $10^{1.54}$ copies/reaction for virus extracts of stool or intestinal contents. The primers and probes specific to the HEV strain in Pig C were primer F2 (142-161: 5'-TCGTGTACAA ACCGAGATTC-3'), primer R2 (267-249 : 5'-GCCCGG CAATATTGTTCTA-3'), Probe Flu2 (172-196 : 5'-GATGC AACCCCGGCAGTTGGTTTTC-FITC-3') and Probe LC2 (198-227: 5'-LCRed640-GCCCTGAGGTACTCTGGAATC ATCCTATCC-3').

\section{Serum Examination}

Antibodies to HEV (IgG and IgM) were assayed by enzyme-linked immunosorbent assay (ELISA) using a commercially available kit (Viragent HEV-Ab kit; Cosmic Corporation, Tokyo, Japan). Peroxidase conjugated anti-pig IgG or anti-pig IgM (Kirkegaard \& Perry Laboratories, Inc., Gaithersburg, Maryland, USA) were applied to detect antigen-bound pig immunoglobulin. The levels of liver cytoplasmic enzyme, alanine aminotransferase (ALT), in sera from pigs were monitored during the experiment.

\section{RESULTS}

One of the pigs (Pig B) infected with HEV showed transient viremia after infection. HEV-RNA was detected transiently in the serum on day 7 after infection and viremia was observed only in pig B at 7 and 11 days after infection (dpi); however, we failed to detect HEV-RNA in serum from another pig (Pig A). The copy number of HEV-RNA in serum was less than $10^{3}$ per $\mathrm{ml}$ at $7 \mathrm{dpi}$. Thereafter, HEV disappeared from the serum and could not be detected during the experiment. Interestingly, HEV-RNAs were first detected in the feces of both pigs on 7 dpi. In contrast to HEV in serum, the copy number of HEV-RNA increased from $10^{5}$ per gram at 7 dpi to $3.4 \times 10^{6}$ per gram at $14 \mathrm{dpi}$ and thereafter, copy numbers of HEV-RNA slightly decreased, but remained at more than $10^{4}$ per gram during the observation period (Fig. 1).

HEV-infected pigs A showed slight increase in hepatic function marker values, but they did not show clinical symptoms during the observation period (Fig. 1B). The levels of ALT were between 28 and 47 (IU/l) in Pigs A and B, and 27 $\mathrm{IU} / 1$ in Pig C. However, histological examination showed that the small diffuse lymphocyte infiltrations in liver were observed in all the HEV infected pigs (Fig. 2). The difference of the degree of cellular infiltration caused by a HEV infection was not recognized in the individual pigs. The detection of HEV antibodies were examined by ELISA. The pigs seroconverted simultaneously for both anti-HEV IgM and -IgG at $18 \mathrm{dpi}$ (Fig. 1C). The patterns of increased antibody titer differed between pigs. Anti-HEV IgM levels in Pig A were lower than in Pig B at 18 dpi (Fig. 1C). ELISA values in the serum from HEV-negative pigs were less than 
0.1 at $\mathrm{OD} 450 \mathrm{~nm}$. The ELISA OD value at $450 \mathrm{~nm}$ in the naturally infected Pig C was 0.55 for anti-HEV IgG and 0.18 for anti-HEV IgM.
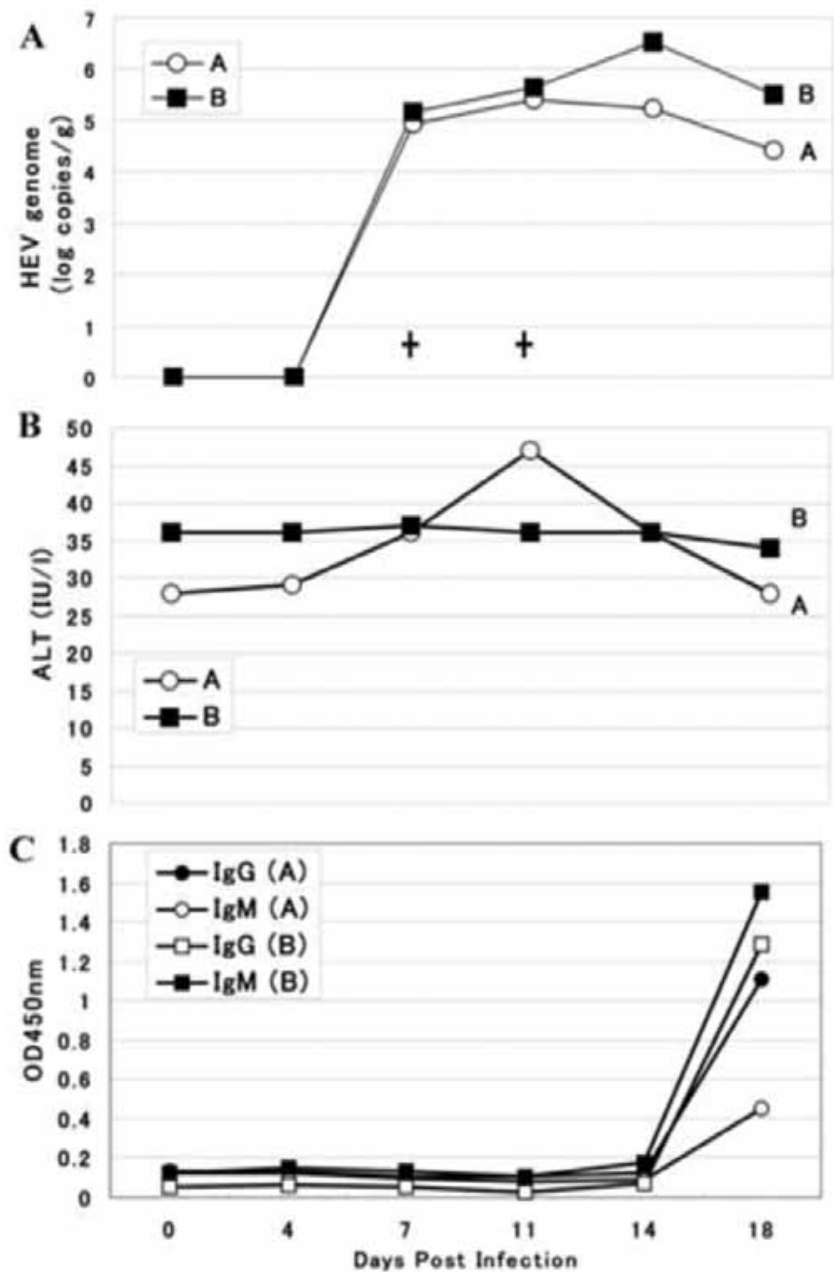

Fig. (1). Experimental inoculation of pigs with HEV. Two pigs (pigs A and B); at 7 and 10 week-old, respectively, were intravenously inoculated with $10^{5}$ copies of genotype $3 \mathrm{HEV}$. (A) Detection of HEV-RNA in serum and feces from infected pigs. Copy numbers of HEV-RNAs in the feces from HEV-infected pigs are shown. Detection of HEV-RNAs in serum samples is shown by $(+)$ on days after infection. (B) Serum ALT in HEV-infected pigs. Pigs $\mathrm{A}$ and $\mathrm{B}$ were monitored for hepatic function. Changes of ALT levels in serum from HEV-infected pigs were monitored during the observation period. (C) ELISA OD values at $450 \mathrm{~nm}$ of anti-HEV $\mathrm{IgG}$ and $\mathrm{IgM}$ in serum from $\mathrm{HEV}$-infected pigs.

To clarify the distribution of HEV-RNA in pigs, tissues samples and intestinal contents from the HEV-infected pigs were applied for RT-PCR. HEV-RNAs were successfully amplified in the liver (including hepatic lymph nodes), small intestine and large intestine (Table 1). In Pig A, HEV-RNA was detected in the liver (right and left lobe), cholecysis and colon. The virus was also distributed in the liver and large intestine (ileum and cecum) in Pig B. Interestingly, HEVRNA was widely distributed in the naturally HEV-infected pig (Pig C). HEV-RNAs were amplified in the liver, cholecysis, duodenum, jejunoileal region of the small and large intestine (cecum, colon and rectum). Next, the virus loads were evaluated between experimentally infected pigs and the naturally infected pig (Table 2). The copy numbers of HEV-
RNA in the liver, cholecysis, bile and feces were quantified by real-time RT-PCR. Intravenously infected pigs (Pigs A and B) showed 5.46 and $4.3 \log$ copies/g in the liver, respectively, which was lower than in the naturally infected Pig C (6.49 log copies/g). HEV-RNA levels in cholecysis differed in Pig A (4.3 log copies/g), Pig B (3.9 log copies/g) and Pig C (6.57 log copies/g). Virus RNA was detected in bile from all pigs, and HEV copy numbers in bile from Pigs A and B were 4.23 and 3.92 (log copies/ml), respectively, but Pig C showed $6.56 \log$ copies $/ \mathrm{ml}$. Feces contained higher copy numbers of HEV-RNA at $18 \mathrm{dpi}$. The copy numbers were 4.43 and $5.52(\log$ copies/g) in Pigs A and B, respectively, and $7.06 \mathrm{log}$ copies/g in Pig C. We also compared the copy numbers of HEV-RNA in intestinal contents from the cecum, colon and rectum in pigs. The copy numbers of HEV-RNA in intestinal contents from Pig C (7.06-7.12 log copies/g) were higher than in Pigs A or B (3.85-5.52 log copies/g) (Table $\mathbf{2}$ ).

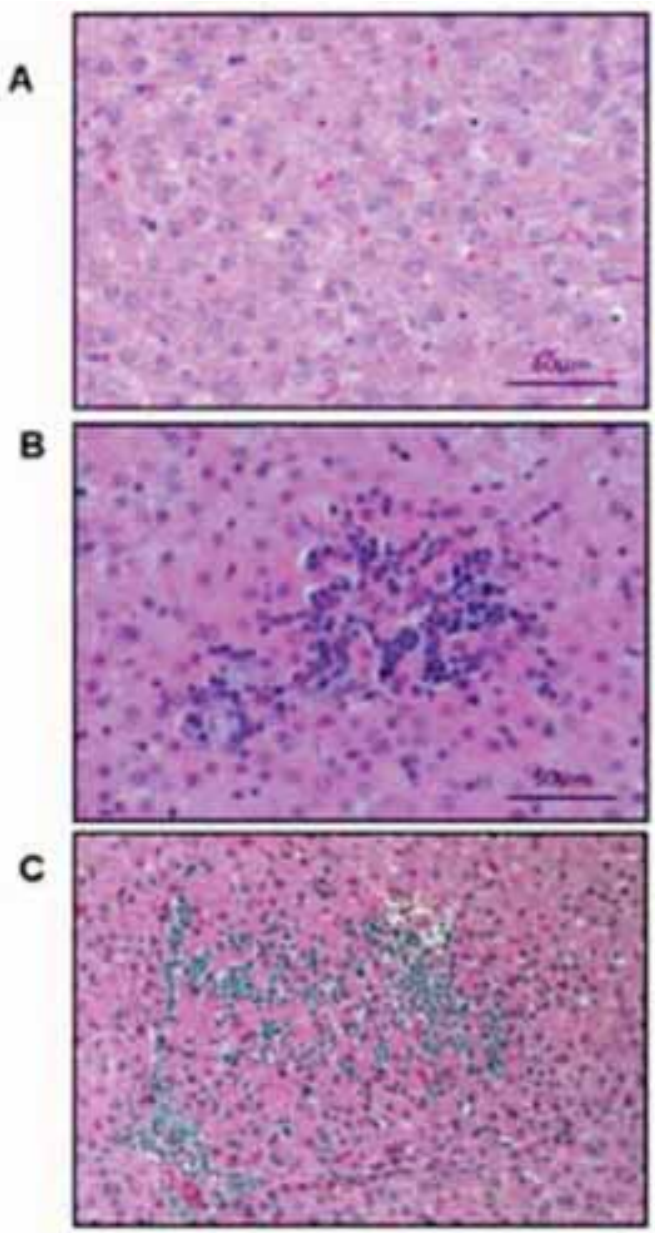

Fig. (2). Histopathology in liver sections from HEV-infected pigs. Histological analysis of liver sections, tissue samples from HEVinfected pigs were fixed in $20 \%$ formaldehyde and embedded in paraffin. The tissue sections were stained with hematoxylin and eosin (HE), and then examined under a light microscope. HEV uninfected control pig D is shown in Panel A. HE staining of liver from the pig $\mathrm{A}$ and $\mathrm{C}$ infected with HEV genotype 3 are shown in Panels B and C.

\section{DISCUSSION}

We examined the distribution and proliferation of $\mathrm{HEV}$ in pigs after transmission via intravenous inoculation. HEV- 
Table1. Distribution of HEV-RNA in HEV-Infected Pigs by RT-PCR Analysis ${ }^{1}$

\begin{tabular}{|c|c|c|c|c|}
\hline Tissues & $\mathbf{A}$ & B & $\mathbf{C}$ & $\mathbf{D}$ \\
\hline Left lateral lobe & - & + & + & - \\
\hline Left medial lobe & + & - & + & - \\
\hline Right medial lobe & + & + & + & - \\
\hline Choledochus & + & + & + & - \\
\hline Duodenum & + & - & + & - \\
\hline Jejunum & - & - & + & - \\
\hline Colon & + & - & + & - \\
\hline Rectum & - & - & + & - \\
\hline Heart & - & - & - & - \\
\hline Kidney & NT & - & - & - \\
\hline Muscle & - & - & - & - \\
\hline Spleen & - & - & NT & - \\
\hline Hepatic lymph node & + & - & + & - \\
\hline
\end{tabular}

${ }^{1}$ Pigs A and B were intravenously inoculated, while Pig C was naturally HEV-infected. Pig D is an uninfected control. NT, not tested.

Table 2. Copy Numbers of HEV in Tissues and Intestinal Contents from HEV-Infected Pigs by Real-Time RT-PCR

\begin{tabular}{|c|c|c|c|}
\hline Samples & $\operatorname{Pig}^{1} \mathbf{A}$ & B & C \\
\hline \hline Liver & 5.4 & 4.3 & 6.49 \\
\hline Choledochus & 4.3 & 3.9 & 6.57 \\
\hline Bile & 4.23 & 3.92 & 6.56 \\
\hline Intestinal contents & & & 7.06 \\
\hline Cecum & 3.85 & 5.29 & 7.12 \\
\hline Colon & 4.43 & 5.52 & 7.06 \\
\hline Feces & 4.43 & & \\
\hline
\end{tabular}

${ }^{1}$ Pigs A and B were intravenously inoculated and data at 18 dpi are shown in this table. Pig C was naturally HEV-infected. Data show log copies/g or ml.

RNA was observed only transiently in intravenously inoculated pig A at 7-11 dpi at low copy numbers (less than 1000 copies/ml), although it was not a mutual observation in all inoculated pigs during the observation period [27]. On the other hand, considerably high copy numbers of HEV-RNAs were detected in the feces from $\mathrm{HEV}$-infected pigs. Although it takes for a week incubation period to detect the HEV genome in fecal samples, two of the pigs showed high copy numbers during the observation period. Thus, a stool sample is a better choice for detection of the HEV genome than serum samples. Detection of antibodies against HEV in experimentally infected pigs have been examined elsewhere $[27,28]$. In this experiment, $\operatorname{IgM}$ and $\operatorname{IgG}$ were first detected at 18 dpi. Interestingly, there was no great difference in the time points of seroconversion between anti-HEV IgG and IgM after HEV infection in both pigs.

HEV was detected in the liver, bile, ileum, cecum, colon, rectal and in intestinal contents; however, we could not detect HEV-RNA in the spleen, muscles, kidney and heart. These results imply that virus replication was limited to re- 
stricted organ regions. The distribution of HEV-RNA in the intestinal tract was not identical in individual pigs (A and $\mathrm{B}$ ). $\mathrm{HEV}$ was detected in the colon in Pig A, but not in Pig B. Ileum and cecum were HEV-RNA-positive regions in Pig B. The copy numbers of HEV-RNA in the intestinal tract were lower than 1000 copies/g. It remains to be clarified whether the virus distributes in all regions of the intestinal tract according to the progression of $\mathrm{HEV}$ infection. In pig $\mathrm{C}, \mathrm{HEV}$ RNAs were detected in all the intestinal tissues and its contents. This pig was reared in a pen with another 10 of same aged pigs which were all infected with HEV. And those pigs were shedding high titer of HEV in the feces. It is possible to infect with HEV via the fecal-oral route continuously. This circumstance may be affected with the copies number of HEV-RNA in the tissues from pig A and B. The route of HEV infection and dose of the virus may affect virus distribution and replication rates in individual pigs. The low copy numbers of HEV distribution seem to be one reason affecting PCR results. Virus shedding in the small intestine should be considered in the distribution of HEV, as described [29].

The copy numbers of HEV-RNA in tissue samples such as the liver and choledochus, including bile, showed similar levels in experimentally infected pigs; however, naturally infected pigs showed significantly higher copy numbers of HEV. The copy numbers were from 100-1000 times higher in naturally infected than in experimentally infected pigs. Pigs are supposed to be infected with HEV via the fecal-oral route continuously, since pigs habitually eat feces naturally. Several epidemiological studies reported HEV shedding in up to 17-week-old pigs [23, 30-32]. An opportunity to come in contact with contaminated feces increases the intake of virus by pigs. Thus, it is possible that pigs have high levels of virus titer in the internal organs by repeated exposure with contaminated feces.

Histopathological observation showed the diffuse lymphoplasmacytic infiltrate in liver, but no apparent necrotic or apoptotic hepatocytes in all the pigs. Halbur et al. [27] reported mild lymphoplasmacytic hepatitis and hepatocellular necrosis in pigs experimentally infected with swine-derived HEV. The inoculated virus titer, virus strain or genotype would influence the pathogenesis to host organs.

In conclusion, intravenous HEV infection leads to high copy numbers of virus shedding in feces without severe hepatitis symptoms in pigs. The real time RT-PCR analysis showed different copy numbers of HEV-RNA in individual organs from HEV-infected pigs. The copy numbers of HEVRNA tended to be higher in the liver and feces rather than the intestinal tract. The copy numbers of HEV-RNA in tissue samples were from 100-1000 times higher in naturally infected than in experimentally infected pigs.

\section{ACKNOWLEDGMENTS}

We greatly appreciate the technical assistance of Ms. M. Sato and Ms. H. Nishigaki in our study. This study was partly supported by a grant-in-aid for the High Technological Research Center (Rakuno Gakuen University) from the Ministry of Education, Science, Sports and Culture of Japan.

\section{REFERENCES}

[1] Emerson SU, Nguyen H, Graff J, Stephany DA, Brockington A, Purcell RH. In vitro replication of hepatitis E virus (HEV) genomes and of an HEV replicon expressing green fluorescent protein. J virol 2004; 78(9): 4838-4846.

[2] Tam AW, Smith MM, Guerra ME, et al. Hepatitis E virus (HEV): molecular cloning and sequencing of the full-length viral genome. Virology 1991;185(1): 120-131.

[3] Meng XJ, Purcell RH, Halbur PG, et al. A novel virus in swine is closely related to the human hepatitis E virus. Proc Natl Acad Sci USA 1997;94(18):9860-9865.

[4] Hsieh SY, Meng XJ, Wu YH, et al. Identity of a novel swine hepatitis $\mathrm{E}$ virus in Taiwan forming a monophyletic group with Taiwan isolates of human hepatitis E virus. J Clin Microbiol 1999; 37: 3828-3834.

[5] Wu JC, Chen CM, Chiang TY, et al. Spread of hepatitis E virus among different-aged pigs: two-year survey in Taiwan. J Med Virol 2002; 66: 488-492.

[6] Nakamura M, Takahashi K, Taira K, et al. Hepatitis E virus infection in wild mongooses of Okinawa, Japan: Demonstration of antiHEV antibodies and a full-genome nucleotide sequence. Hepatol Res 2006; 34(3): 137-140.

[7] Okamoto H, Takahashi M, Nishizawa T, Fukai K, Muramatsu U, Yoshikawa A. Analysis of the complete genome of indigenous swine hepatitis E virus isolated in Japan. Biochem Biophys Res Commun 2001; 289(5): 929-936.

[8] Mitsui T, Tsukamoto Y, Yamazaki C, et al. Prevalence of hepatitis $\mathrm{E}$ virus infection among hemodialysis patients in Japan: evidence for infection with a genotype $3 \mathrm{HEV}$ by blood transfusion. J Med Virol 2004; 74(4): 563-572.

[9] Takahashi K, Iwata K, Watanabe N, et al. Full-genome nucleotide sequence of a hepatitis $\mathrm{E}$ virus strain that may be indigenous to Japan. Virology 2001; 287(1): 9-12.

[10] Tanaka Y, Takahashi K, Orito E, et al. Molecular tracing of Japanindigenous hepatitis E viruses. J Gen Virol 2006; 87(Pt 4): 949954.

[11] Ohnishi S, Kang JH, Maekubo H, Takahashi K, Mishiro S. A case report: two patients with fulminant hepatitis E in Hokkaido, Japan. Hepatol Res 2003; 25(2): 213-218.

[12] Suzuki K, Aikawa T, Okamoto H. Fulminant hepatitis E in Japan. N Engl J Med 2002; 347(18): 1456.

[13] Kato M, Taneichi, K, Matsubayashi K. A mini-outbreak of HEV infection in those who enjoyed Yakiniku party: one died of fulminant hepatitis. Kanzo (Japanese). 2004; 45: 688

[14] Matsuda H, Okada K, Takahashi K, Mishiro S. Severe hepatitis E virus infection after ingestion of uncooked liver from a wild boar. J Infect Dis 2003; 188(6): 944.

[15] Tamada Y, Yano K, Yatsuhashi H, Inoue O, Mawatari F, Ishibashi H. Consumption of wild boar linked to cases of hepatitis E. J Hepatol 2004; 40(5): 869-870.

[16] Tei S, Kitajima N, Takahashi K, Mishiro S. Zoonotic transmission of hepatitis E virus from deer to human beings. Lancet 2003; 362(9381):371-373.

[17] Boxall E, Herborn A, Kochethu G, et al. Transfusion-transmitted hepatitis $\mathrm{E}$ in a 'nonhyperendemic' country. Transfusion medicine 2006; 16(2): 79-83.

[18] Irshad M, Sharma Y, Dhar I, Singh J, Joshi YK. Transfusiontransmitted virus in association with hepatitis A-E viral infections in various forms of liver diseases in India. World J Gastroenterol 2006; 12(15): 2432-2436.

[19] Lee CK, Chau TN, Lim W, Tsoi WC, Lai ST, Lin CK. Prevention of transfusion-transmitted hepatitis $\mathrm{E}$ by donor-initiated self exclusion. Transfus Med 2005; 15(2): 133-135.

[20] Khuroo MS, Kamili S, Yattoo GN. Hepatitis E virus infection may be transmitted through blood transfusions in an endemic area. $\mathrm{J}$ Gastroenterol Hepatol 2004; 19(7): 778-784.

[21] Matsubayashi K, Nagaoka Y, Sakata H, et al. Transfusiontransmitted hepatitis E caused by apparently indigenous hepatitis E virus strain in Hokkaido, Japan. Transfusion. 2004; 44(6): 934-940.

[22] Arankalle VA, Chobe LP, Walimbe AM, Yergolkar PN, Jacob GP Swine HEV infection in south India and phylogenetic analysis (1985-1999). J Med Virol 2003; 69(3): 391-396.

[23] Banks M, Heath GS, Grierson SS, et al. Evidence for the presence of hepatitis E virus in pigs in the United Kingdom. Vet Rec 2004; 154(8): 223-227.

[24] Caron M, Enouf V, Than SC, Dellamonica L, Buisson Y, Nicand E. Identification of genotype 1 hepatitis $\mathrm{E}$ virus in samples from swine in Cambodia. J Clin Microbiol 2006; 44(9): 3440-3442. 
[25] Cooper K, Huang FF, Batista L, et al. Identification of genotype 3 hepatitis $\mathrm{E}$ virus (HEV) in serum and fecal samples from pigs in Thailand and Mexico, where genotype 1 and 2 HEV strains are prevalent in the respective human populations. J Clin Microbiol 2005; 43(4): 1684-1688.

[26] Choi C, Chae C. Localization of swine hepatitis E virus in liver and extrahepatic tissues from naturally infected pigs by in situ hybridization. J Hepatol 2003; 38(6): 827-832.

[27] Halbur PG, Kasorndorkbua C, Gilbert C, et al. Comparative pathogenesis of infection of pigs with hepatitis $\mathrm{E}$ viruses recovered from a pig and a human. J Clin Microbiol 2001; 39(3): 918-923.

[28] Meng XJ, Halbur PG, Haynes JS, et al. Experimental infection of pigs with the newly identified swine hepatitis E virus (swine HEV), but not with human strains of HEV. Arch Virol 1998; 143(7): 1405-1415.
Williams TP, Kasorndorkbua C, Halbur PG, et al. Evidence of extrahepatic sites of replication of the hepatitis $\mathrm{E}$ virus in a swine model. J clin Microbiol 2001; 39(9): 3040-3046.

Garkavenko O, Obriadina A, Meng J, et al. Detection and characterisation of swine hepatitis E virus in New Zealand. J Med Virol 2001; 65(3): 525-529.

Huang FF, Haqshenas G, Guenette DK, et al. Detection by reverse transcription-PCR and genetic characterization of field isolates of swine hepatitis $\mathrm{E}$ virus from pigs in different geographic regions of the United States. J Clin Microbiol 2002; 40(4): 1326-1332.

Nakai I, Kato K, Miyazaki A, et al. Different fecal shedding patterns of two common strains of hepatitis $E$ virus at three Japanese swine farms. Am J Trop Med Hyg 2006: 1171-1177. 